\title{
Novel Experimental Investigation of Supercapacitor Ageing during Combined Life-Endurance and Power- Cycling Tests
}

\author{
Dr. Dimitri Torregrossa, Pr. Mario Paolone \\ Distributed Electrical System Laboratory (DESL) \\ Swiss Federal Institute of Lausanne (EPFL) \\ Lausanne, Switzerland \\ dimitri.torregrossa@epfl.ch, mario.paolone@epfl.ch
}

\begin{abstract}
This paper proposes a new experimental investigation of the ageing mechanisms of supercapacitors. Starting from the main ageing mechanisms of these devices reported in the literature, the paper proposes a suitably developed procedure aimed at evaluating their ageing during combined life endurance and power cycling tests. In particular, the effect of the temperature (usually referred as life endurance) is evaluated in supercapacitors solicited with an a-priori defined power cycle. The effects of the temperature during the so-called recovering phase are also investigated. Each experimental finding is discussed by taking into account the phenomenon of the residual charge redistribution inside the supercapacitor electrodes.
\end{abstract}

Keywords - supercapacitor; ageing; life endurance test; power cycling test; recovering phase, charge redistribution.

\section{INTRODUCTION}

The peculiar energy/power densities of the supercapacitors (SCs) make these devices as the ideal power sources in applications requiring high-power densities like: fast charging of electric vehicles, medical devices, universal power supply (UPS) applications, elevators, pulsed laser, etc. All these applications are characterised by an elevated number of cycles applied to the power source. In this respect, the adequate evaluation of SC life models represents an important aspect to be investigated.

As analysed in [1], the non-reversible electrochemical reactions (i.e., parasitic electrochemical reactions increasing the decomposition of the electrodes) taking place in a SC have a large influence on its life expectancy since the energy storage mechanism of this device is not purely electrostatic.

The effects of these reactions depend strongly on the SC voltage $\left(V_{S C}\right)$, temperature $\left(T_{S C}\right)$ and current $\left(I_{S C}\right)$ delivered by the device. As above-mentioned, SCs can be used for particular applications requiring high values of delivered current that might range from few Amperes up to several or thousands of Amperes. Additionally, the environments where these devices are operating might be characterized by temperatures (e.g., $50^{\circ} \mathrm{C}-65^{\circ} \mathrm{C}$ ) close to the boiling point of the SC electrolytes (i.e., $78^{\circ} \mathrm{C}$ for the tetrafluoroborate).

In this respect, the ageing mechanism has to be investigated under these conditions in order to define adequate ageing tests and infer relevant life expectancy models. In the literature, several works on this subject have been done and they can be grouped in two main categories:

a) life endurance (LE), also called life calendar test [1-8];

b) power-cycling test (PC) [7-11].

The first group (i.e., the LE tests), consists in controlling the targeted SC temperature $\left(T_{S C}\right)$ and voltage $\left(V_{S C}\right)$ into a specific environment in order to analyse their effects on the life endurance expectation. During these tests the SC is not delivering any current. Since the so-called SC charge redistribution phenomena takes place, the $\mathrm{SC}$ voltage decreases in agreement to what shown in [12-15]. Consequently, the targeted SC has to be charged with a very low current in order to keep the $V_{S C}$ constant.

In the second category of tests (i.e., the PC tests), the environment temperature is kept constant to a rated value (e.g., $25^{\circ} \mathrm{C}$ ) and charge/discharge cycles, with a specific $I_{S C}$, are applied to the SC in order to infer the life endurance expectation of the device.

It should be underlined that the electrochemical reactions occurring during the ageing process of a SC, are partially reversible $[4,10]$. In this respect, in some works, a so-called regeneration, or regenerative, phase is observed if the following conditions are satisfied: (i) the $T_{S C}$ and/or the $V_{S C}$ is reduced during a LE test in comparison with their starting values; (ii) the $I_{S C}$ is reduced during a PC test in comparison with its starting value. With specific reference to PC tests, this phenomenon has been investigated in $[9,10]$ and demonstrated to be of extreme importance in life assessment of SCs.

However, the main limitation of these works is that the assessment of the $\mathrm{SC}$ recovering phase at high temperatures are not investigated.

In [1-2] the experimental description of the ageing processes involved during a LE test with different $T_{S C}$ and $V_{S C}$, along with an ageing model formulation based on experimental evidences, is presented. These papers have described the variation of the SC impedance during accelerated LE test and have presented an extrapolation of the SC lifetime by using a heuristic approach. Nerveless, the phenomenon of the SC capacitance recovery is not taken into account.

Authors of the work presented in [3] claim that the most important ageing processes of the $\mathrm{SC}$ are driven by both $T_{S C}$ 
and $V_{S C}$. Consequently, they did not take into account the power cycling effects on the evaluation of the SC life.

In $[5,6,11]$ some investigations have been performed separately for LE and PC tests without exploring the SC recovering phase and, also, the effects of hightemperatures/high-current on the SC life.

On the contrary, in $[4,7,9,10]$ the Authors have performed a detailed characterization of the SC ageing process during combined LE and PC test. They observed, and in some specific cases, described a clear recovering phase. The results presented in these works appear extremely interesting although the PC test refer to $I_{S C}$ amplitudes comparable to the SC rated current (in this respect, it is worth observing that $\mathrm{SC}$ can be used with cycles characterised by $I_{S C}$ much larger than the SC rated current). Additionally, in $[4,7,9,10]$ the influence of the temperature on the duration/quantification of the $\mathrm{SC}$ regeneration phase during combined $\mathrm{PC}$ and LE tests has not been addressed.

The above-described drawbacks have motivated this paper. In particular, we have analysed the effect of high $T_{S C}$ during combined LE and PC tests in case of $I_{S C}$ much larger (one order of magnitude) than the SC rated current. Additionally, the effect of high $T_{S C}$ during the $\mathrm{SC}$ recovering phase is analysed as well.

The paper is structured as follows: in section II an overview of the two main SC ageing mechanisms, along with the description of the SC recovering phase, are detailed; in section III the experimental test bench and test procedure for the automatic-online characterization of the SC ageing process is described; section IV presents the experimental results for the combined LE and PC tests along with a temperature characterization of the recovering phase. Finally, the last section summarizes the contribution of this work.

\section{BRIEF SUMMARY OF THE SC AgEING PHENOMENA}

\section{A. Power cycling test}

The main factor influencing the SC ageing process during a power cycling test is the RMS value of the current, $I_{S C}$, during a defined charge/discharge cycle. Indeed, the degradation of the SC during a PC test is related to the amount of charges flowing through the electrolyte-electrode interface involving a de-cohesion of the carbon composing some parts of the electrodes.

Other factors that might have an influence and that are, in general, not considered are: (i) the rest time, $T_{R E S T}$, between two cycles influencing the SC regeneration phenomenon; (ii) the current wave shape used for the cycle (as it can involve additional thermal stresses [9]).

The investigation of the above-described ageing mechanism when $I_{S C}$ is higher than the rated one, deserves specific investigations. With this purpose, in the work here presented the value of the SC current has been deliberately chosen to be one order of magnitude higher than the rated one.

\section{B. Life endurance test}

The two main factors involving the ageing during a LE test are the $V_{S C}$ and the environment temperature $T_{E}$ (in what follows we will assume $T_{E}=T_{S C}$ as the tests have been performed into controlled climatic conditions for which we can reasonably assume the $\mathrm{SC}$ in thermal equilibrium with the external environment).

Concerning the effects of the $T_{S C}$ on the SC life, it seems that the ageing mechanism is triggered by the accumulation of impurities on the surfaces of the SC electrodes leading a decrease on the cell capacitance value and an increase of the equivalent resistance series $(E S R)$ [9]. In this respect, the aim of the work here presented is to investigate the influence of a LE test at high temperature along with a PC ageing test.

\section{SC recovering phase}

The recovering phase following a $\mathrm{PC}$ has been discussed in [9]. In this paper the capacitance-recovery, observed after a PC, has been associated to three main factors: (i) the duration of the SC rest after the PC; (ii) the number of cycles between two subsequent rests and (iii) the cumulated value of cycles of the whole ageing test.

Concerning the physical explanation of the SC recovery, it has been associated to the following mechanism. During a PC ageing, a certain charge imbalance takes place inside the porous structure of the electrodes-electrolyte interface reducing the active surface area and, consequently, the SC capacitance. When the PC test is stopped, the redistribution phenomenon related to the mitigation of this charge gradient, takes place with a time constant relatively important (thousands of seconds) and, consequently, it is possible to observe a return to a so-called 'thermodynamic steady state' associated to higher capacitance values.

To the best of our knowledge, the literature dealing with the effects of the temperature on the recovering phase following a PC test is quite scarce. Since the whole process is strictly linked to the redistribution phenomenon [14], we find worth investigating the effects of the temperature on the recovery-capacitance mechanism.

\section{EXPERIMENTAL ASSESSMENT OF THE SC AGEING}

The targeted SC has a rated capacitance value of $365 \mathrm{~F}$, a rated voltage of $V_{N}=2.75 \mathrm{~V}$ and it is cycled with different current profiles having different waveshapes, peak values and time durations. The common factor is represented by peak current values chosen to be tens of times higher than the SC rated current (for the adopted $\mathrm{SC}$ its rated current was of $30 \mathrm{~A}$ (a) $\left.25^{\circ} \mathrm{C}\right)$.

\section{A. Experimental test bench and procedure}

Fig. 1 illustrates the block scheme of the experimental test setup. It is composed of four main elements: (i) a $365 \mathrm{~F}$ supercapacitor inserted into a climatic chamber where the environmental temperature, $T_{E}$, is kept constant to a predefined value; (ii) a power source working in the following $V / I$ ranges 0-80 $\mathrm{V}$ and 0-120 $\mathrm{A}$; (iii) an electronic load working in the following $V / I$ ranges $0-80 \mathrm{~V}$ and 0-200 A; (iv) control PC where, a suitable realised software developed using the LabView programming environment, is able to perform the monitoring and control the whole system. Concerning the electronic load and power supply, they are characterised by an overall bandwidth from DC to $1 \mathrm{kHz}$. Concerning measurement system, the $V_{S C}$ voltage is directly sampled using 
an analog-to-digital converter operating a 16 bits with a maximum sampling frequency of $100 \mathrm{kHz}$ and characterised by a bandwidth from $\mathrm{DC}$ to $100 \mathrm{kHz}(-3 \mathrm{~dB})$. The $I_{S C}$ is measured towards a dedicated hall-effect sensor characterised by an overall bandwidth from DC to $100 \mathrm{kHz}(-3 \mathrm{~dB})$. Also for the $I_{S C}$, the analog output of the current sensor is sampled with a analog-to-digitan convert having the same characteristics of the one used for the $V_{S C}$.

In Fig. 1 the black lines represent the control signals from the control PC towards the power source and the electronic load. During the charging phase the power source is receiving the set points of the SC charging current and the SC final voltage to be reached at the end of the charge $\left(V_{F}\right)$. During the $\mathrm{SC}$ discharge the electronic load receives the waveform of the SC discharge current $I_{S C}(t)$. The red lines of Fig. 1 indicate the transfer of the power (i.e., from the power sources to the SC during the charging phase and from the SC to the electronic load during the discharging phase). The green line indicates the measurement signals: the $V_{S C}, I_{S C}$ and $T_{S C}$ are continuously measured.

The climatic chamber where the $\mathrm{SC}$ is hosted allows to control its internal temperature in the range $28-360{ }^{\circ} \mathrm{C}$.

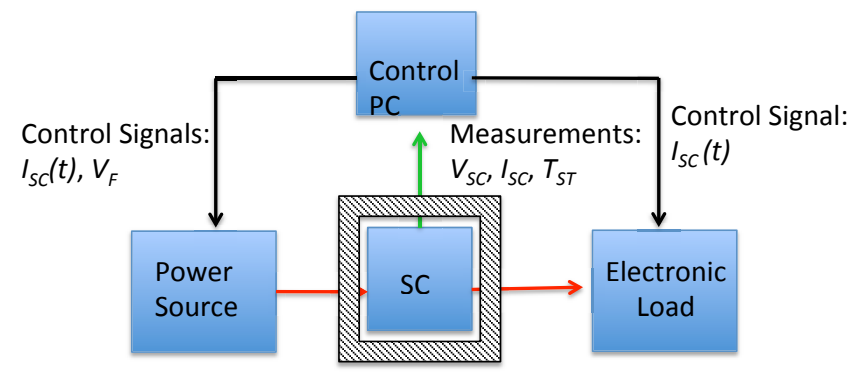

Fig. 1. Block scheme of the experimental test setup.

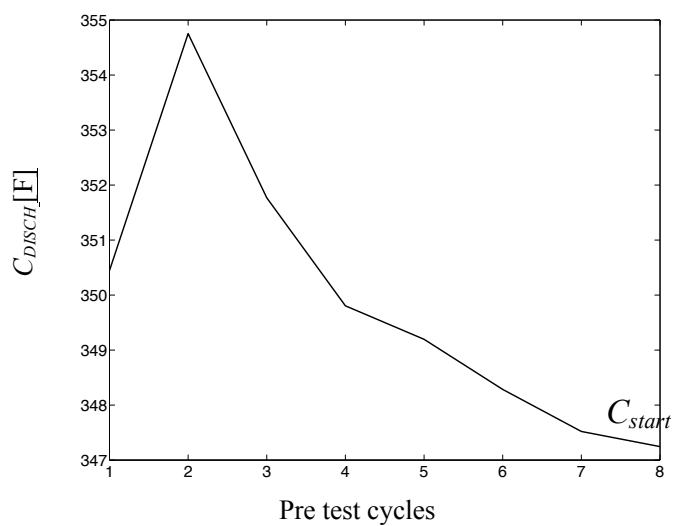

Fig. 2. Variation of the SC capacitance during the first seven cycles.

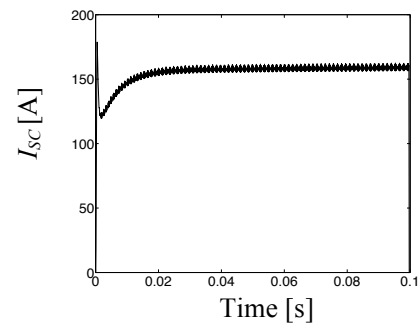

a) First Current Profile b) Second Current Profile

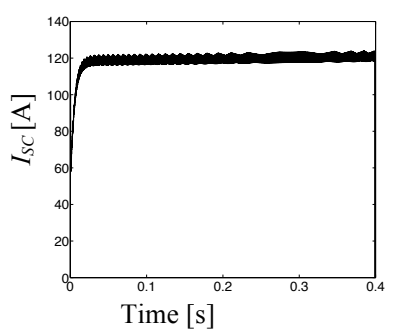

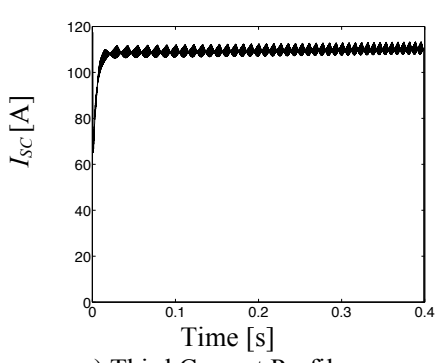

c) Third Current Profile

Fig. 3. Current profiles adopted for the SC PC test: a) first current profile, b) second current profile, 3 ) third current profile.

\section{B. Experimental procedure to evaluate the SC ageing}

This paragraph summarizes the procedure followed to characterize the ageing mechanism and the parameters that are periodically measured on the targeted SC. This procedure is composed of four main steps listed below and described in detail in the next sub-sections:

- pre-test;

- LE test along with PC test;

- measurement of SC parameters considered for its ageing;

- assessment of the SC recovery.

C. Pre-test

We start from a SC that has been completely discharged, namely short-circuited for 3 days. Such a starting condition guarantees the absence of residual charges inside the SC.

The pre-test consists in cycling the SC with chargedischarge cycles. The charging is realised with a constant current of 10 A while the discharge is realised by a constant load of $0.1 \Omega$. The final voltage for the $\mathrm{SC}$ charge is $V_{F}=2.45 \mathrm{~V}$. Note that, in order to largely mitigate the SC life dependency against $V_{F}$, the value of this parameter has been selected to be well below the SC rated voltage $V_{N}=2.7 \mathrm{~V}$ [1-2]. This pre-cycle is performed a certain number of times (in general below 10) up to the moment when the so-called residual charge $(\Delta Q)$ that remains stored in the SC reaches a steady value [14]. As can be inferred from [14], the value of usable SC capacitance, defined as the ratio between the charges furnished, or extracted, and the correspondent voltage variation on the SC, depends strongly on $\Delta Q$. From this starting point, it is necessary to define the value of the SC capacitance, $C_{\text {start }}$, to be considered during the ageing test for evaluating the ageing mechanism and, consequently, the loss of the SC capacitance. In this respect, it is worth observing that the rated capacitance provided by the SC manufacturer is related to a SC completely discharged. However, since the above-defined usable SC capacitance varies during the first cycles, the value of $C_{\text {start }}$ that we have been assumed is the one corresponding to the conditions where the $\Delta Q$ has reached its steady value. In this respect, Fig. 2 illustrates the variation of the usable SC capacitance for the first 8 cycles. During the pre-test phase, the usable SC capacitance varies from $355 \mathrm{~F}$ to $347 \mathrm{~F}$. It is interesting to observe that the SC usable capacitance closest to the $\mathrm{SC}$ rated one appears at the beginning of the pre-test when the $\Delta Q$ is minimum. In this respect, the value of usable capacitance that we have considered for the ageing assessment 
is equal to $347.4 \mathrm{~F}$ reached at the end of the pre-test (i.e., at the end of the $8^{\text {th }}$ cycle).

\section{LE and PC tests}

Once the pre-test phase is completed, the ageing test related to the combined LE and PC test can start. In the work here presented several combined ageing tests have been performed.

The characteristics of the LE test are: (i) environmental temperatures set points $T_{E}$ of $28^{\circ} \mathrm{C}, 35^{\circ} \mathrm{C}, 40^{\circ} \mathrm{C}$ and $55^{\circ} \mathrm{C}$, (ii) the test starts once the average temperature of the SC measured by three thermocouples (on the bottom, up and lateral side of the SC) is equal settled $T_{E}$.

The characteristic of the PC test are: (i) after each discharge, the SC is charged with a constant current of $10 \mathrm{~A}$ until the $\mathrm{SC}$ reaches a final voltage value $V_{F}=2.45 \mathrm{~V}$, (ii) the $\mathrm{SC}$ is discharged with the current profile given by Fig. 3; (iii) the rest time $T_{\text {rest }}$ between two subsequent shots composing the whole discharge cycle shown in Fig. 3, has been chosen in the range of few tens of seconds; (iv) the ageing test is periodically stopped each 500 discharges in order to carry out the characterization test described as follows.

The current profiles summarized in Fig. 3 simulates a given operating condition of the SC. Therefore, the outcomes of the $\mathrm{SC}$ ageing will be influenced by these profiles.

\section{E. Measurement of SC parameters considered for its ageing}

The procedure for assessing the SC parameters is structured as follows: (i) the SC is charged with a constant current of $10 \mathrm{~A}$ until the $\mathrm{SC}$ reaches a final voltage value $V_{F}=2.45 \mathrm{~V}$, during this phase the $\mathrm{SC}$ input electrode resistance $E S R$, is evaluated by measuring the voltage drop across the SC terminals; (ii) the power generator is turned off and the charge redistribution phenomenon is observed and recorded for 20 minutes, the value of $V_{S C}$ at $10 \mathrm{~min}$ (namely $V_{S C 10}$ ) and 20 min (namely $V_{S C 20}$ ) are measured; (iii) the SC is discharged with a constant resistance $R_{\text {load }}$ equal to $0.1 \Omega$ until the $V_{S C}$ reaches $100 \mathrm{mV}$. During this last phase the capacitance is computed as follows:

$$
C_{d i s c h}=\frac{\Delta Q_{d i s c h}}{\Delta V_{d i s c h}}
$$

where $\Delta Q_{\text {disch }}$ is the time integral of the current delivered by the $\mathrm{SC}$ and $\Delta V_{\text {disch }}$ the voltage variation during the phase (iii).

Moreover, for estimating the ageing mechanism in the decay voltage appearing during the redistribution phases, the quantity $V_{F}-V_{S C 10}$ has been evaluated during each test.

It is worth observing that during the redistribution taking place in phase (ii) a potential start of the SC recovering might take place (we remember that the recovering phenomenon starts to be considerable at least after one hour). In order to compensate this possible effect, the SC is discharged with a very low value of resistance $(0.1 \Omega)$ and, consequently, with a current profile characterised by several tens of Amperes at the

${ }^{1}$ This value of $T_{\text {rest }}$ has been selected in order to avoid any possible regenerative phenomena [9]. beginning of the discharge to few $\mathrm{mA}$ at the end of the discharge.

The time needed to complete the 500 discharges and to assesse the SC parameters is around 4 hours. Note that the deep discharge of the SC until $V_{S C}=100 \mathrm{mV}$ takes around 20 minutes. The duration of this last time window depends strongly on the value of $V_{S C}$ required at the end of the deep discharge. The value of $100 \mathrm{mV}$ has been choses as a trade-off between the duration of the test and the evaluation of the SC extracted charge.

\section{F. Assessment of the SC recovery}

Once the number of the pre-defined cycles is reached, the targeted SC is kept into a temperature-controlled chamber at the targeted temperature $T_{E}$. In this phase, since the SC is not delivering any electric current, the recovering phase starts to take place. During this phase, the procedure described in the sub-section $\mathrm{E}$ is performed every 2 hours in order to evaluate the capacitance recovery.

\section{EXPERIMENTAL RESULTS}

\section{A. Temperature effects on combined power cycling and life endurance test}

Four combined LE and PC tests have been performed at four different temperatures $T_{E}$, namely $28^{\circ} \mathrm{C}, 35^{\circ} \mathrm{C}, 40^{\circ} \mathrm{C}$ and $55^{\circ} \mathrm{C}$ with the same charge/discharge cycles of Fig. 3. Fig. 4 and Fig. 5 illustrate the evolution of the three main monitored quantities, namely, $V_{F}-V_{S C 10}, E S R$ and $C_{D I S C H}$ during a combined $\mathrm{LE}$ and $\mathrm{PC}$ test at $28^{\circ} \mathrm{C}$ and $35^{\circ} \mathrm{C}$, respectively. Fig. 6 and Fig. 7 illustrate the evolution of the $C_{D I S C H}$ at $40^{\circ} \mathrm{C}$ and $55^{\circ} \mathrm{C}$ respectively. Fig. 8 illustrates the comparison of the evolution of $C_{D I S C H}$ at $35^{\circ} \mathrm{C}, 40^{\circ} \mathrm{C}$ and $55^{\circ} \mathrm{C}$. In this case the value of $C_{D I S C H}$ of each measurement is reported in per-unit of the $C_{\text {start }}$. The increasing of the $T_{S C}$ during the cycling was equal to $1{ }^{\circ} \mathrm{C}$. Therefore, we can reasonably assume that the temperature-ageing source is the one corresponding to the environment temperature. The following observations can be inferred from the obtained experimental investigations.

a) The $V_{F}-V_{S C 10}$ decreases considerably at the beginning of the test and, after, it exhibits almost a constant trend. The initial variation can be justified by the fact that the quantity $\Delta Q$ has not reached the maximum value. After the first cycles, $\Delta Q$ reaches a steady value and, as a consequence, the redistribution phenomenon is more important and, consequently, the decay voltage is less important [14]. As during the ageing tests the $\Delta Q$ remains essentially unvaried, we have that the decay voltage is almost constant.

b) The ESR is almost constant in spite of the majority of the results obtained in other previous works related to LE test $[1,2]$. This behaviour can be justified by the fact that, during a PC test, there is a higher quantity of charges passing through the electrode-electrolyte interface compared to a simple LE test. We can reasonably assume that, during the PC tests, some of the impurities located on the electrodes surfaces (that are the main reason of ageing during a LE test) are removed by the high charge flows due to the values of the selected SC 
currents. The impact of the temperature on the ESR value during a LE will be investigated in further works.

c) In agreement with other works presented in the literature (e.g., [1-4]), the SC capacitance decreases during a combined PC and LE test. In particular, $C_{D I S C H}$ decreases with a pseudoexponential behaviour (it should be underlined that, during the pre-test, there is a loss of capacitance not related to any ageing phenomenon).

d) The decrease of $C_{D I S C H}$ is more important at higher temperatures. This finding is in agreement with other works for typical LE ageing test (e.g. $[1,2,7]$ ). At $35^{\circ} \mathrm{C}$ after the delivery of $0.6 \mathrm{MAh}$, this loss is equal to $2 \%$, at $40{ }^{\circ} \mathrm{C}$ is 2.5 $\%$ and at $55^{\circ} \mathrm{c}$ is $5.5 \%$. A common finding in [1], highlights that for an increase of $10^{\circ} \mathrm{C}$ of $T_{S C}$, the related capacitance loss doubles. It seems that during a combined PC and LE test, in view of what explained in $b$ ), this experimental evidence is not respected. In this respect, it will be interesting to compare the capacitance loss with a classical LE test at the same temperature. This specific aspect deserves further specific investigations.

\section{B. Temperature effects on the recovering phase}

Fig. 9 illustrates the time evolution of $C_{D I S C H}$ during the recovering phase at $28^{\circ} \mathrm{C}, 40^{\circ} \mathrm{C}$ and $55^{\circ} \mathrm{C}$. In this graph, the value of $C_{D I S C H}$ has been expressed in per unit of the value of the SC capacitance reached just before the assessment of the recovery (i.e., the value of capacitance reached by the $\mathrm{SC}$ at the end of the PC and LE ageing tests). The most important observations are summarised below.

For each recovering phase, two main sub-phases can be detected. The first one is characterised by the capacitance recovery taking place even if $T_{E}$ is higher than the rated one. During this specific sub-phase, the ageing mechanism related to the PC disappears but the one related to the LE is still present. In the second sub-phase the effect of LE ageing mechanism starts to be stronger than the recovering effect due to the interruption of the PC. In this specific second sub-phase the targeted SC restarts to age along with a capacitance loss. The duration of these two sub-phases largely depends on the temperature and on the amount of Ah delivered by the SC before stopping the PC. In particular, at $28^{\circ} \mathrm{C}$, the recovering phase holds for 10 hours with a capacitance increasing of $3.5 \%$; at $40^{\circ} \mathrm{C}$ the same sub-phase holds for 4.5 hours with a capacitance increasing of $1.8 \%$; at $55^{\circ} \mathrm{C}$ the recovering phases does not take place and the SC continues to age. This last results, to the best of our knowledge, has not been detected in previous works. It appears to be an important behaviour and it highlights the effect of temperature during the recovering phase subsequent to combined LE and PC tests. The influence of the temperature during $\mathrm{PC}$ test will deserve specific investigations in the future.

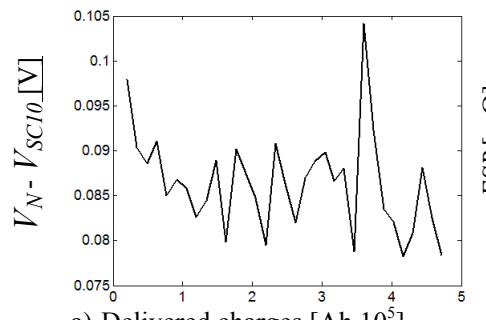

a) Delivered charges $\left[\mathrm{Ah} 10^{5}\right]$

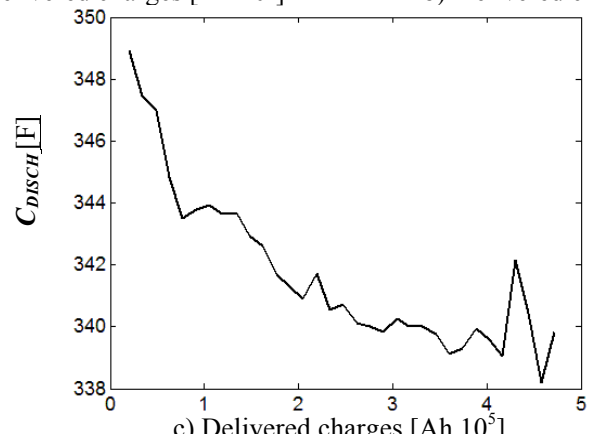

Fig. 4. $C_{D I S C H}$, ESR and $V_{F^{-}} V_{S C 10}$ evolution during a combined the ageing test at $28^{\circ} \mathrm{C}$.

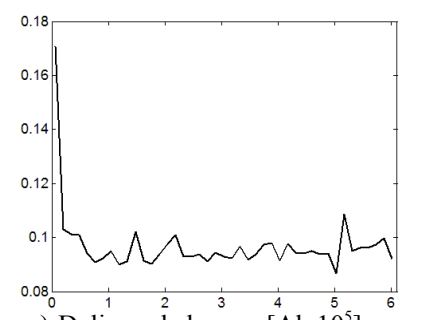

a) Delivered charges ${ }^{2}\left[{ }^{4}\right.$ Ah $\left.10^{5}\right]$
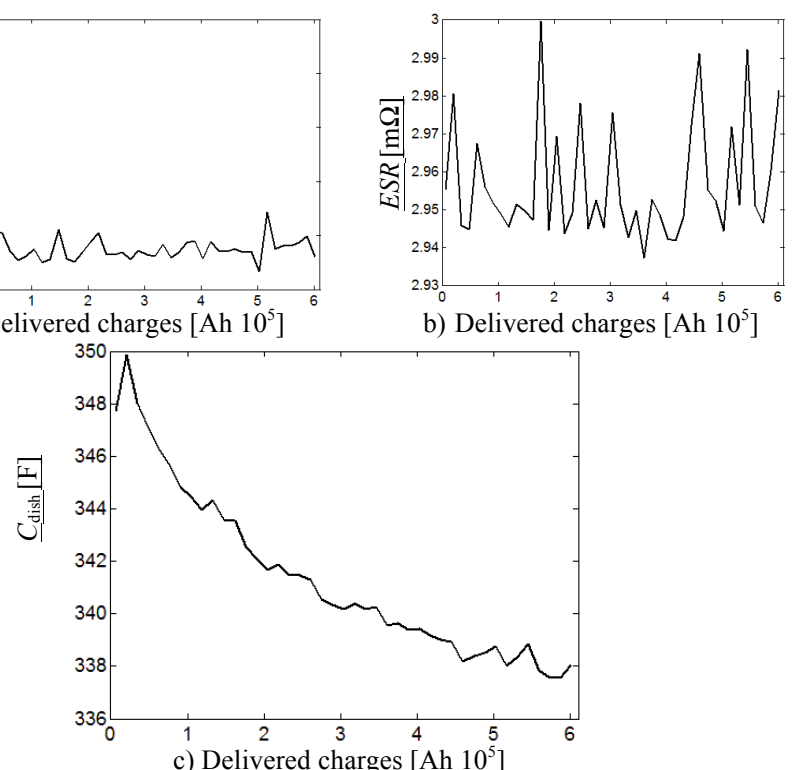

Fig. 5. $C_{D I S C H}, E S R$ and $V_{F^{-}} V_{S C I 0}$ evolution during a combined ageing test at $35^{\circ} \mathrm{C}$.

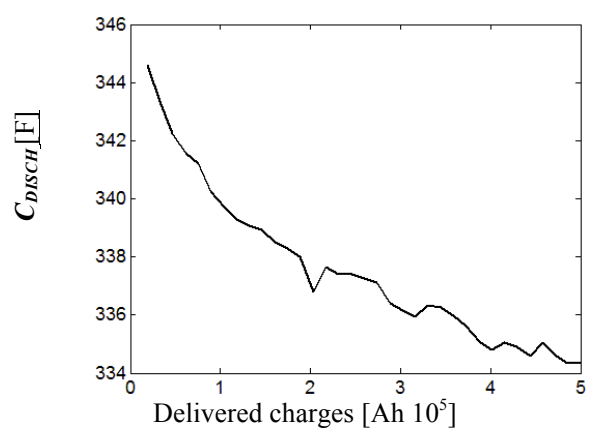

Fig. 6. $C_{D I S C H}$, evolution during a combined ageing test at $40^{\circ} \mathrm{C}$. 


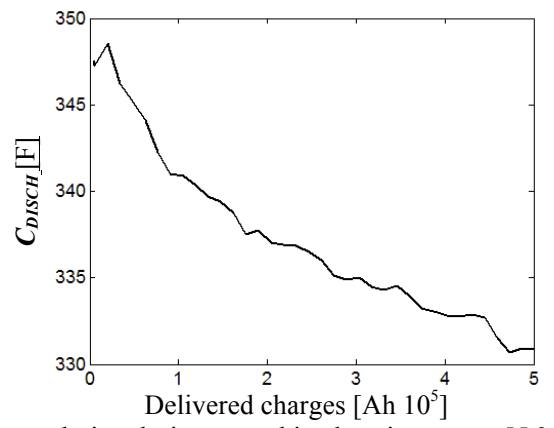

Fig. 7. $C_{D I S C H}$, evolution during a combined ageing test at $55^{\circ} \mathrm{C}$.

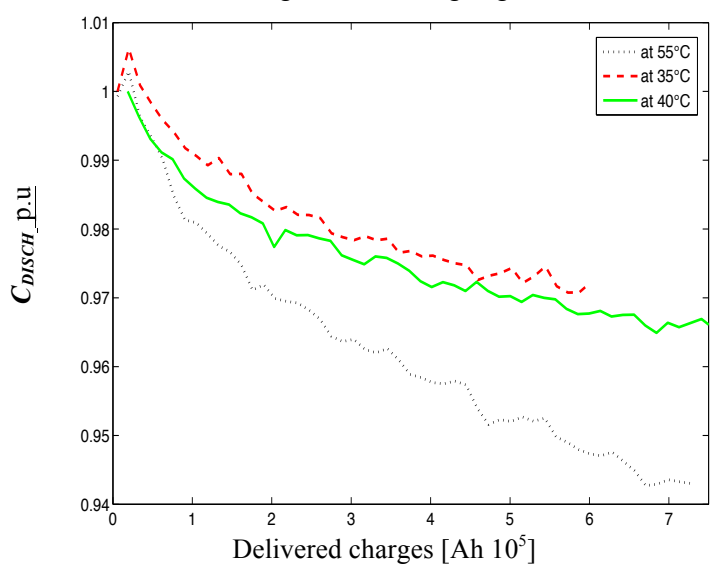

Fig. 8. Evolution of $C_{D I S C H}$, during combined LE and PC test at $35^{\circ} \mathrm{C}, 45^{\circ} \mathrm{C}$ and $55^{\circ} \mathrm{C}$.

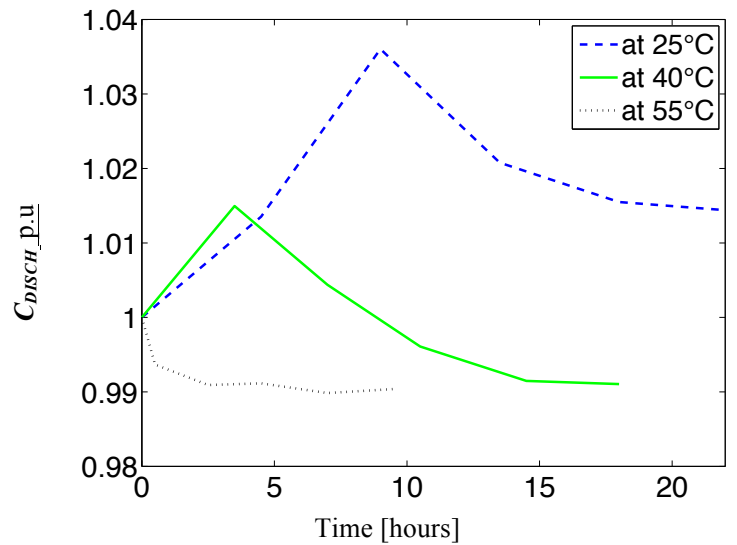

Fig. 9. Evolution of $C_{D I S C H}$, during the recovering phase at $25^{\circ} \mathrm{C}, 40^{\circ} \mathrm{C}$ and $55^{\circ} \mathrm{C}$.

\section{CONCLUSIONS AND Future OUTLOOKS}

The work here presented has illustrated an experimental study aimed at assessing the ageing mechanism of SC during life endurance, power cycling and combined ageing tests. In particular, this study has been carried out by means of an experimental characterization of the temperature effects on combined PC and LE test along with an experimental investigation of the SC recovery.

The experimental results have been obtained by using an automatic procedure to estimate the main SC parameters for assessing its ageing. In particular, it has been observed that the ESR does not increase significantly during a combined ageing test. The capacitance loss of the targeted SC increases significantly for higher temperatures but it does not double its value for a $10^{\circ} \mathrm{C}$ of increasing of environment temperature. Additionally, the recovering phase subsequent a combined LE and PC test, has been observed. The main finding is that, for high temperatures (i.e., starting from $55^{\circ} \mathrm{C}$ ), the recovering phase does not take place since the ageing mechanism related to the temperature seems to be the predominant one. In total, eight SC samples have been used for experimentally observing the reported results during combined ageing LE and PC tests.

Starting from the above-summarized findings, further research will be dedicated to a complete investigation of the SC recovering phase by taking into account the value of delivered Ah for evaluating the SC capacitance recovery at different environment temperatures. Further, the obtained results will be used to infer an analytical SC ageing model that accounts both LE and PC stresses.

\section{ACKNOWLEDGMENT}

The authors gratefully acknowledge the Swiss Innovation and Technology Committee (CTI) to make possible these activities concerning the experimental characterization of supercapacitors. The authors thankfully acknowledge $\mathrm{M}$. Braglia and M. Robert for their help in carrying out the experimental investigations.

\section{REFERENCES}

[1] Oliver Bohlen, Julia Kowal, Dirk Uwe Sauer, "Ageing behaviour of electrochemical double layer capacitors Part I. Experimental study and ageing model", Journal of Power Sources 172 (2007) 468-475.

[2] Oliver Bohlen, Julia Kowal, Dirk Uwe Sauer, "Ageing behaviour of electrochemical double layer capacitors Part II. Lifetime simulation model for dynamic applications", Journal of Power Sources 173 (2007) 626-632.

[3] D. Linzen, S. Buller, E. Karden, R.W De Doncker, "Analysis and evaluation of charge-balancing circuits on performance, reliability, and lifetime of supercapacitor systems," IEEE Transactions on Industry Applications, , vol.41, no.5, pp. 1135-1141, Sept.-Oct. 2005.

[4] O. Briat, J.-M. Vinassa, N. Bertrand, H. El Brouji, J.-Y. Delétage, E. Woirgard, "Contribution of calendar ageing modes in the performances degradation of supercapacitors during power cycling", Microelectronics Reliability vol.50 (2010) 1796-1803.

[5] A. Hammar, P. Venet, R. Lallemand, G. Coquery, G. Rojat, "Study of Accelerated Aging of Supercapacitors for Transport Applications," IEEE Transactions on Industrial Electronics, vol.57, no.12, pp.3972-3979, Dec. 2010.

[6] R.Kötza, M. Hahna, R. Gallay, "Temperature behavior and impedance fundamentals of supercapacitors"

[7] O. Briat , J.-M. Vinassa, N. Bertrand, H. El Brouji, E. Woirgard, "Impact of Calendar Life and Cycling Ageing on Supercapacitor Performance," IEEE Transactions on Vehicular Technology, vol.58, no.8, pp.3917-3929, Oct. 2009.

[8] N. Rizoug, P. Bartholomeus, P.Le Moigne, "Study of the Ageing Process of a Supercapacitor Module Using Direct Method of Characterization," IEEE Transactions on Energy Conversion, vol.27, no.2, pp.220-228, June 2012.

[9] R. Chaari, O. Briat, J.Y. Deletage, J.Vinassa, "Performances regeneration of supercapacitors during accelerated ageing tests in power cycling," Power Electronics and Applications (EPE 2011), pp.1-7, Aug. 30 2011-Sept. 12011.

[10] W. Lajnef, J. Vinassa, O. Briat, H. El Brouji, S. Azzopardi, E. Woirgard, "Quantification of ageing of ultracapacitors during cycling tests with current profile characteristics of hybrid and electric vehicles applications," IET Electric Power Applications, vol.1, no.5, pp.683-689, Sept. 2007.

[11] M. Uno, K. Tanaka, "Accelerated ageing testing and cycle life prediction of supercapacitors for alternative battery applications," IEEE Telecommunications Energy Conference (INTELEC), 9-13 Oct. 2011, pp.1-6. PC.

[12] Y, Diab, P. Venet, H. Gualous, G. Rojat; "Self-Discharge Characterization and Modeling of Electrochemical Capacitor Used for Power 
Electronics Applications," Transactions on Power Electronics, IEEE, vol.24, no.2, pp.510-517, Feb. 2009.

[13] B W Ricketts, C Ton-That, «Self-discharge of carbon-based supercapacitors with organic electrolytes » in Journal of Power Sources Vol. 89, 2000, pp. 64-69.

[14] D. Torregrossa, M. Bahramipanah, E. Namor, R. Cherkaoui, M. Paolone, "Improvement of Dynamic Modeling of Supercapacitor by Residual Charge Effects Estimation," IEEE Transactions on Industrial Electronics, in press.

[15] D. Torregrossa, M. Bahramipanah, R. Cherkaoui, M. Paolone «Experimental Evidences of Redistribution Phenomenom in Supercapacitors and Consequent Dynamic Modeling Improvement t» in Power Tech Conference, 16-20 June, 2013. 